\title{
Correction to: skeletal muscle mechanics: questions, problems and possible solutions
}

W. Herzog

\section{Correction}

In Fig. 3a of the original manuscript [1], the passive force at the beginning of the force-time history (approximately from 0 to $1 \mathrm{~s}$ ) of each of the black and orange traces was interchanged in the coloring process. This was an error in the artwork preparation, not the original data. The corrected figure is shown below.

I would like to thank Brent Raiteri for alerting me to this error.

Received: 22 December 2017 Accepted: 5 February 2018

Published online: 07 March 2018

\section{Reference}

1. Herzog W. Skeletal muscle mechanics: questions, problems and possible solutions. J Neuroeng Rehabil. 2017;14:98.

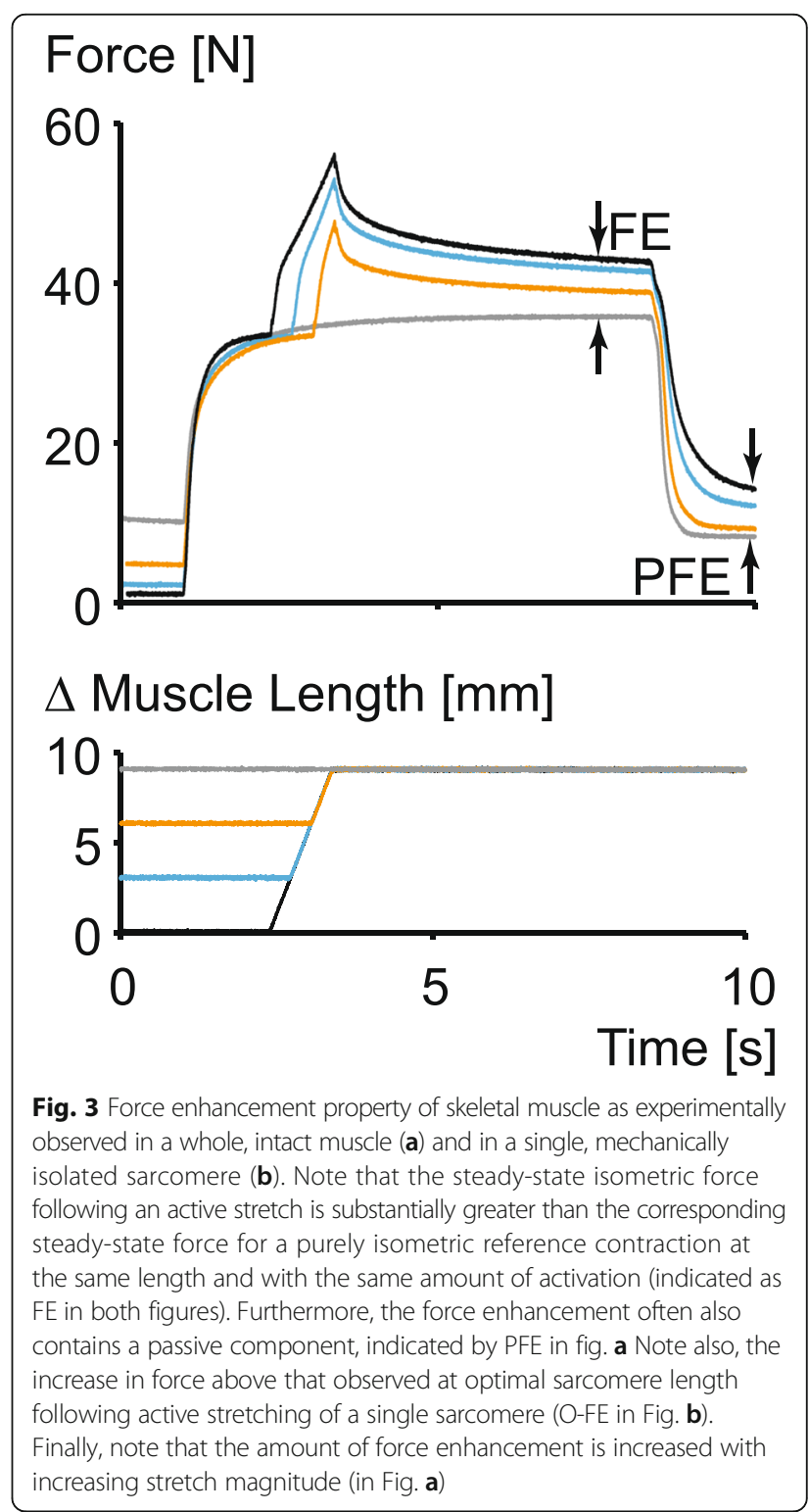

Correspondence: wherzog@ucalgary.ca

Faculty of Kinesiology, University of Calgary, 2500 University Dr, Calgary, AB T2N-1N4, Canada

(c) The Author(s). 2018 Open Access This article is distributed under the terms of the Creative Commons Attribution 4.0 International License (http://creativecommons.org/licenses/by/4.0/), which permits unrestricted use, distribution, and reproduction in any medium, provided you give appropriate credit to the original author(s) and the source, provide a link to the Creative Commons license, and indicate if changes were made. The Creative Commons Public Domain Dedication waiver (http://creativecommons.org/publicdomain/zero/1.0/) applies to the data made available in this article, unless otherwise stated. 